\title{
Nacho Duque García, De la soledad a la utopía. Fredric Jameson, intérprete de la cultura postmoderna. Zaragoza: Prensas Universitarias de Zaragoza, 2012, 248 págs.
}

El libro que aquí reseñamos, De la soledad a la utopía. Fredric Jameson, intérprete de la cultura postmoderna, no es una monografía cualquiera. Es uno de los primeros estudios amplios publicados en castellano sobre Fredric Jameson. Jameson, nacido en Cleveland en 1934, es, según escribió Perry Anderson en The Origins of Postmodernity (1998), el escritor marxista estadounidense más importante del último tercio del siglo XX. Opinión que no solo cabe atribuir a sus insoslayables escritos sobre el posmodernismo y la posmodernidad, sino que bien podríamos fechar a partir de su decisiva introducción en la teoría literaria estadounidense de lo que Perry Anderson llamó "marxismo occidental" (Marxism and Form; publicado en 1971). De profesión crítico literario especialista en literatura francesa primero, tal y como atestigua su tesis doctoral sobre Jean-Paul Sartre (The Origins of a Style; publicada en 1961), y en literatura comparada después, Jameson ha escrito sobre muchos otros temas no estrictamente literarios. Reuniones de ensayos como The Modernist Papers (2007), Valences of the Dialectic (2009), The Ideologies of Theory (1988), Arqueologies of the Future (2005) o Signatures of the Visible (1990) se mueven con excepcional soltura y brillantez en los campos de la arquitectura, pintura, cinematografía, historia, ciencia ficción y filosofía. Seguir el ritmo y la amplitud de la mirada caleidoscópica de Jameson resulta, sencillamente, imposible, pero intentarlo es un viaje, metáfora necesaria de este libro, que el autor ha intentado llevar a buen puerto. Y ya podemos adelantar que lo ha conseguido.

Ciertamente, el viaje es la trama que Nacho Duque García emplea como organizadora de este estudio. La casualidad está lejos de tener algo que ver en esta elección. Doctor en filosofía por la Universidad de Zaragoza y asociado, tanto en el estilo como en el contenido, al grupo de investigación filosófica Riff-Raff coordinado por el profesor José Luis Rodríguez García, Duque concibe el viaje como una hermenéutica que bien pareciera haber estado construyendo para llegar a comprender el espectacular viraje dialéctico que todo texto de Jameson implica. Si en Palabras de viaje. Estética y hermenéutica del viaje (2007) se anunciaba una exploración de este motivo, en su De la soledad a la utopía asistimos a la madurez de este planteamiento, como si de algún modo la única monografía posible sobre Jameson implicase la metáfora del viaje, por un lado, y como si la exploración del viaje como hermenéutica solo pudiese completarse por medio de la dialéctica jamesoniana.

La mirada de Jameson, como su estilo, se resiste a la forma de escritura clásica anglosajona. La dialéctica para Jameson, entendida como lo que él mismo llamó "metacomentario", está lejos de someterse a las exigencias de la lectura rápida. Siguiendo en este aspecto a Adorno, aunque con un inconfundible gusto por la hegeliana Aufhebung, el estilo de Jameson pretende, por un lado, romper el contenido de la forma implícito en lo que aparentemente es inocente, y, por otro, es en sí mismo el contenido de lo que Jameson quiere dar a conocer. Según Terry Eagleton, el estilo de Jameson es su propio contenido; un estilo que se despliega de los más pequeño a lo más grande, imantando y reuniendo en un latigazo final todas las partes aparentemente inconexas de una formación social que no parecía responder a la representación realista. 
Ciertamente, en opinión de Terry Eagleton ("Jameson and Form", en NLR) este estilo, como sucediera con Georg Lukács, parece ofertar una compensación utópica al presentar en una sola constelación (Darstellung) conexiones insospechadas entre, digamos, el estilo modernista de la descripción de un paisaje en Lord Jim (o un cuadro impresionista) y el capitalismo imperialista de fines del siglo XIX. Leer a Jameson es embarcarse en una aventura o en una montaña rusa. Es esa excitación intelectual, que ofrece una visión total e inesperada del mundo de la cultura, lo que ha seguido atrayendo a generaciones de lectores a la obra de Jameson. Y es en esa misma gratificación que proporciona esos descubrimientos, y esa sensación de dominio de loque-es, donde reside el problema político que se infiere de su obra. Conocer la necesidad no significa, a pesar de Spinoza, ser libre.

En el mundo del "fin de la historia", Jameson (The Seeds of Time; 1994) se tuvo que contentar con delimitar los contornos de las antinomias del mundo actual, que él llamó posmoderno o capitalista tardío. Advirtió que el éxito de Francis Fukuyama no se debía solo a una maniobra publicitaria, sino que expresaba un bloqueo de la imaginación política y una victoria real del capitalismo. Late Marxism (1990) fue la vindicación (y ajuste de cuentas con) de un T. W. Adorno entendido como refugio contra la miseria del "nuevo orden mundial". Pero es entonces cuando el motivo jamesoniano (y moderno) por excelencia, y sin cuyo concurso no tiene sentido este libro, surgió con más fuerza que nunca en Arqueologies of the Future (2005): la utopía. Pues el viaje de Jameson, como el mismo que propone aquí Nacho Duque García, es este mismo: de la soledad y la derrota posmoderna, de su presente permanente producto de la propia miseria de la modernidad llamada condición posmoderna, a una permanente y desafiante utopía que, como nos advierte al final de Valences of the Dialectic (2009), ya no es un lugar más allá de la Historia, sino que es, precisamente, el no-lugar, ese loque-no-es y puede ser, que conlleva la historicidad del presente y de la propia Historia.

Este viaje en forma de lectura estructura los diferentes capítulos de De la soledad a la utopía. De la lectura solitaria de la posmodernidad, cuyas diferentes e inconexas manifestaciones Jameson engarzó como una sola lógica cultural del capitalismo tardío en su más impresionante hallazgo (Postmodernism, or, The Cultural Logic of Late Capitalism; 1991), publicado originalmente en 1984, a la exploración de los motivos, impulsos y proyectos utópicos que venía descifrando en todo tipo de producto cultural desde la década de 1970, el viaje es un desplazamiento de la mirada que recorre las diferentes caras de la modernidad. Es esta modernidad, agotada en su victoria de lo Mismo sobre lo Otro, muerta de éxito una vez el globo entero, incluyendo la naturaleza y el inconsciente, han sido sometidos a la reproducción capitalista, la que da lugar a esta suerte de compensación o pesadilla espacial llamada posmodernidad. En la posmodernidad ya no hay lugares a los que Jim pueda huir a ocultar su vergüenza. Pero en la propia aventura moderna de Jim estaba su muerte posmoderna: su huida solo podía darse en tanto que el sistema capitalista en su forma imperial permitía que él, oficial blanco británico, estuviese huyendo de algo que finalmente habría de alcanzarle. Y es que la Historia, escribió Jameson en su manifiesto metodológico más importante (The Political Unconscious, publicado en 1981), es una violenta Necesidad que por mucho que queramos olvidarla podemos estar seguros que ella no habrá de olvidarse de nosotros. 
Por esta razón, el viaje que proponen tanto Jameson como Duque es tan inevitable como deseable. Dicho de otro modo, como escribió Jameson en su inequívoco e imprescindible "Marxism and Historicism" (recogido en The Ideologies of Theory), todo contacto con el pasado implica que el presente habrá de ser pasado de un futuro y, además, que en ambos casos se trata de un contacto colectivo entre modos de producción, clases y formaciones sociales. El viaje, por tanto, es posibilitado por una Necesidad que, mediante una lectura alegórica que tanto el Jameson de Brecht and Method (1998) como el propio Duque proponen, transforma lo más individual y aislado, en una totalidad impensable, en una comunidad social inesperada cuya constitución historiza nuestro presente con consecuencias imprevisibles. Este viaje es necesariamente histórico, en tanto que arroja al presente a un campo de batalla del que 1989 parecía haberlo sacado. Para Jameson el marxismo es historicismo, y no puede entenderse de otro modo. No es casualidad que su ya célebre "Always historicize!" sea la frase que abre The Political Unconscious. Es esta generosidad olímpica la que le permitió reconstruir diversos sistemas de pensamiento opuestos al marxismo -como hizo con el estructuralismo (The Prison-House of Language; 1972)-; detectar sus contradicciones radicadas en la represión de la Historia, y resolver sus ausencias en un movimiento dialéctico que tiene mucho de integración y cancelación de ese sistema. Jameson es un marxista hegeliano cuya forma de leer debe tanto a Lukács como a Jacques Lacan. Por ello la Historia, que en sí misma es irrepresentable, es un misterio cuyas huellas nos configuran y cuya reconstrucción - que Jameson mantuvo viva para la teoría literaria a lo largo de la deconstructivista década de 1980-, habrá de mostrar insospechados inconscientes políticos tanto como mantener viva la idea de una alternativa o impulso utópico reprimidos.

A pesar de no explorar con la adecuada profundidad la concepción de la historicidad del crítico estadounidense, De la soledad a la utopía captura como hasta ahora no se había hecho en castellano su difícil y fascinante lectura alegórica. Ciertamente, para un lector neófito puede hacerse complicado seguir el curso del viaje que Duque propone. Es un estudio que debe muy poco al renovado intencionalismo al que la historia intelectual nos tiene acostumbrados desde la publicación de The Logic of the History of Ideas (1999), de Mark Bevir, y cuya versión tradicional ha dominado esta subdisciplina durante décadas. Pero tampoco puede decirse que sea una obra contextualista. Ciertamente, el libro de Nacho Duque adolece de una falta de concreción histórica que no puede pasarse por alto. En su afán por alejarse de la monografía y por capturar el viaje de Jameson, de su lectura alegórica y del propio acto de leer, De la soledad a la utopía no agota el diálogo que sugiere la relación del crítico literario con sus autores de referencia (E. Auerbach, K. Burke, G. Lukács, G. W. Hegel o J-P. Sartre), ni tampoco explora a fondo la capacidad del marxismo hegeliano de Jameson para enfrentar, comprender, desarmar y reapropiar sistemas opuestos a su pensamiento. Siendo esto una pequeña insuficiencia, que no invalida lo dicho más arriba, el principal problema del libro de Nacho Duque no se encuentra en este detalle, sino en la, en nuestra opinión, insuficiente historización de los textos del personaje.

Efectivamente, la lectura de Nacho Duque nos lleva del impresionante diagnóstico histórico del presente posmoderno hasta su alternativa utópica. Sin duda alguna, esta es una forma legítima y eficazmente política de reorganizar el material jamesoniano. Pero es una narrativa que deja inexploradas algunas de las genealogías de sus principales conceptos y visiones. No tanto porque Duque no se ocupe de textos anteriores a esa 
captura prodigiosa de la lógica cultural del capitalismo tardío que realizó en 1984, sino porque no los historiza con la suficiente precisión, objetivo que seguramente hubiese requerido, amén de un libro más voluminoso, una trama diferente a la de este viaje. Así nos quedamos con la duda de si el pesimista diagnóstico de Jameson sobre la condición posmoderna es producto de su propia modernidad hegeliana, esto es, de una visión marcada por la mirada lúgubre de lo que Perry Anderson llamó "marxismo occidental". O de si su inversión utópica es una compensación estética de lo que trajo la década de 1970 y el aislamiento académico de su marxismo, que dejó a los intelectuales norteamericanos como náufragos en sus islotes universitarios. O, para decirlo como sencillamente explicó Martin Jay, si su uso del concepto "capitalismo tardío" - acuñado por Ernst Mandel- no deja de ser el producto de una posición típicamente occidental, moderna y marxista clásica, ya que bien podríamos estar, después de la incorporación de los BRICS, en un capitalismo que acaba de comenzar.

Esta insuficiente historización de su posición académica e ideológica, que creemos necesaria para un completo entendimiento de la obra jamesoniana, contrasta con las excelentes radiografías que Nacho Duque ofrece de las relaciones que establece Jameson con el estructuralismo y el postestructuralismo. Historizar no significa exponer un contexto y dejar que el sujeto se explique por mera reducción o relación más o menos directa con lo expuesto. Bien al contrario, implica descubrir cómo el inconsciente político o la ideología organiza un texto. Historizar supone la reconstrucción de las condiciones de posibilidad y los actos de exclusión o represión de un texto o un discurso. Lo que de hecho implica una lectura alegórica que en cada gesto nos descubre un tema nuevo, un aspecto desconocido, y los conecta con algo más grande cuyo contorno era insospechado hasta que ha sido reconstruido. Esta es la intención del viaje de Jameson: de la soledad de la academia, que bien podría haber dado lugar a una plena historización de Jameson dentro de ella, y del aislamiento del presente permanente posmoderno, a la diferencia utópica de una colectividad por encima de la escisión y la división del trabajo.

Esta lectura alegórica del texto, o "metacomentario", nos lleva más allá del dualismo intencionalismo/contextualismo. $\mathrm{Y}$ es este viaje el que hace de Jameson una parada obligatoria para todo historiador intelectual que no quiera renunciar ni al texto ni a la lucha de clases entendida como proceso histórico. La lectura aparece entonces como un acto colectivo que, si bien corre el peligro de convertirse en una Aufhebung compensatoria, no se detiene en ningún momento. Pues cuando este acto simbólico individual se descubre inesperadamente colectivo; cuando en este viaje se encuentra el último nivel de lectura -que es el de los modos de producción y su transición y coexistencia- que en The Political Unconscious se nos sugiere y mediatiza nuestra experiencia, inmediatamente Jameson nos sitúa en ese proceso irrepresentable y colectivo llamado Historia, que nada tiene que ver con la certidumbre de plomo y la manida "síntesis" con la que se ha querido simplificar siempre el pensamiento de Hegel. Para Jameson la dialéctica no es un juego de suma cero ni una trampa al juego del solitario. La Historia, bien al contrario, está compuesta de semillas impredecibles del tiempo. Y dentro de ellas viaja siempre un reverso (y principio) negativo al que Jameson, en tanto marxista hegeliano, le concede la esperanza futura de realizarse como impulso positivo: la utopía. 
Creemos, aun a riesgo de caer en la exageración, que pocos libros dedicados a Jameson han propuesto una forma narrativa tan certeramente apegada al procedimiento de lectura del crítico estadounidense como lo hace este De la soledad a la utopía. La historización de Jameson es cualquier cosa menos lineal o estática. A veces el lector solo encuentra la solución, o la propia propuesta, al final del texto, cuando todo lo que se insinuaba incomprensible adquiere la simplicidad y clarividencia de una desconcertante Darstellung. Por ello, desde el punto de vista de los que disfrutamos descubriendo el mundo explorado por Jameson, el libro de Nacho Duque García solo puede ser bienvenido y celebrado. El viaje que nos ofrece no es tan propio de una dialéctica afirmativa como la obra del escritor norteamericano. En este punto, se siente que Duque García no es tan deudor del "marxismo occidental" y la modernidad como lo es Jameson. Pero no por ello su oferta, más allá del excelente estudio que presenta de la obra de Jameson, resulta poco atractiva. Al contrario, el viaje hermenéutico de De la soledad la utopía. Fredric Jameson, intérprete de la cultura postmoderna, es el de una lectura que nos lleva, sin garantía de certeza ninguna, de lo individual hermético a lo colectivo esperanzado. Lo que propone es un viaje que no se detiene, como tampoco lo hace la Historia. Una lectura alegórica, en definitiva, que descubre las innumerables huellas históricas que nos (des)componen como sujetos y nos sitúa a las puertas de una posibilidad que no cabe ni en la obra de Jameson ni en la recomendable lectura de este excelente libro.

Miguel Ángel Sanz Loroño

Universidad de Zaragoza

sanzlor@unizar.es

Fecha de recepción: 27 de mayo de 2015.

Fecha de aceptación: 3 de junio de 2015.

Publicado: 30 de junio de 2015.

Para citar este artículo: Miguel Ángel Sanz Loroño, "Nacho Duque García, De la soledad a la utopía. Fredric Jameson, intérprete de la cultura postmoderna. Zaragoza: Prensas Universitarias de Zaragoza, 2012, 248 págs.", Historiografías, 9 (enero-junio, 2015): pp. 140-144.

http://www.unizar.es/historiografias/historiografias/numeros/9/sanz1.pdf 